\title{
Nutritional Composition of Ten Persimmon Cultivars in the "Ready-to-Eat Crisp" Stage. Effect of Deastringency Treatment
}

\author{
Pedro Novillo1, Cristina Besada1, Li Tian², Almudena Bermejo, Alejandra Salvador ${ }^{*}$ \\ ${ }^{1}$ Postharvest Department, Instituto Valenciano de Investigaciones Agrarias, Moncada, Valencia, Spain \\ ${ }^{2}$ Department of Plant Sciences, University of California, Davis, CA, USA \\ Email: 'salvador ale@gva.es
}

Received 28 August 2015; accepted 26 October 2015; published 29 October 2015

Copyright (C) 2015 by authors and Scientific Research Publishing Inc.

This work is licensed under the Creative Commons Attribution International License (CC BY).

http://creativecommons.org/licenses/by/4.0/

(c) (i) Open Access

\section{Abstract}

Traditionally persimmons have been consumed over-ripened to avoid astringency perception. However, the introduction of new technology that removes astringency while preserving fruit firmness has allowed the commercialization of "ready-to-eat crisp" fruits. Several studies have evaluated the nutritional composition of over-ripened persimmons and have claimed that they are a good source of primary and secondary metabolites that are favourable for human health. Yet very little is known about the nutritional composition of persimmons in the "ready-to-eat crisp" stage. In this context, we determined the main nutritional compounds in ten popular persimmon cultivars, including astringent cultivars ("Rojo Brillante", "Tone Wase", "Giboshi", "Kaki Tipo", "Aizumishirazu-A", “Giombo", "Hachiya”) and non-astringent cultivars ("O'gosho", "Hana Fuyu" and "Jiro"). To this end, fruits were harvested when their texture was firm, and soluble polyphenols content, total antioxidant capacity and main sugars, organic acids and carotenoids were evaluated. In those astringent cultivars at harvest, the changes in nutritional compounds associated with applying deastringency treatment with high $\mathrm{CO}_{2}$ concentration were determined. Our results revealed the main sugars (glucose, fructose and sucrose), organic acids (citric acid, malic acid and succinic) and carotenoids ( $\beta$-cryptoxanthin, lutein, violoxanthin, zeaxanthin, and $\beta$-carotene) present in the flesh of crisp persimmons. At harvest the content of these metabolites vastly varied among cultivars; astringent cultivars showed higher soluble polyphenols and greater antioxidant capacity, and presented higher contents of sugars and organic acids than non-astringent ones. The deastringency treatment applied to astringent cultivars resulted in a drastic loss of soluble polyphenols and total antioxidant capacity, and induced changes in carotenoids and sugars composition.

\section{Keywords}

Persimmon, Crispy Texture, Nutritional Composition, Antioxidant Capacity, Deastringency

"Corresponding author.

How to cite this paper: Novillo, P., Besada, C., Tian, L., Bermejo, A. and Salvador, A. (2015) Nutritional Composition of Ten Persimmon Cultivars in the "Ready-to-Eat Crisp" Stage. Effect of Deastringency Treatment. Food and Nutrition Sciences, 6, 1296-1306. http://dx.doi.org/10.4236/fns.2015.614135 


\section{Treatment}

\section{Introduction}

An important feature of persimmon cultivars (Diospyros kaki L.) is that some produce astringent fruits due to the high soluble tannin content in flesh. Astringency is the sensation that results when soluble tannins bind salivary proteins and cause them to precipitate or aggregate, which leads to a rough "sandpapery" or dry sensation in the mouth. According to the level of flesh soluble tannins at harvest, persimmon cultivars can be classified into two general categories: astringent and non-astringent persimmons (also called "sweet” persimmons) [1].

Astringent cultivars, unlike non-astringent ones, require postharvest treatment to remove astringency prior to commercialising fruits. Traditionally, fruits from astringent cultivars were consumed in the over-ripening stage, which can be achieved naturally on trees or by applying exogenous ethylene. Apart from loss of astringency in both cases, fruits suffer significant flesh softening, which makes postharvest handling difficult. In recent decades, several deastringency techniques have been assayed to remove astringency while preserving the firm texture of fruits. Nowadays, the most widely used technique to remove fruit astringency without it affecting firmness is based on exposing fruits to anaerobic conditions (95\% - 98\% $\mathrm{CO}_{2}$ for $24-36 \mathrm{~h}$ ), which results in ready-to-eat non-astringent fruits with a crispy texture.

Due to health awareness campaigns, the general public has become more interested in foods that support and promote health. Thus the importance of fruit bioactive metabolites as protective compounds in human nutrition and health is well recognised. Indeed persimmons are considered a good source of readily available carbohydrates and bioactive compounds, like polyphenols and carotenoids [2] [3]. Studies in vivo and in vitro have suggested a relevant role of persimmon extracts in cell protection against free radicals to prevent damage to important biological membranes [4]-[6].

Despite several research works having studied the chemical composition of different persimmon cultivars [3] [7] [8], it is difficult to compare the data obtained in the aforementioned studies because, besides the cultivar, many other factors, e.g. maturity stage, environmental factors and technological process, affect the content of the primary and secondary metabolites [3] [9] [10]. Most data refer to over-ripened fruit and it is necessary to know the chemical composition of “ready-to-eat crisp” fruits, as mentioned previously by Giordani et al. [3]. Unfortunately, very little information about the effect of deastringency treatment on phytonutrients is available.

Therefore, the aim of this research was to study the nutritional composition of ten persimmon cultivars in the "ready-to-eat crisp" stage by establishing the main primary and secondary metabolites, such as sugars, organic acids, carotenoids and soluble polyphenols. The effect of deastringency treatment on nutritional composition was also evaluated in astringent cultivars.

\section{Materials and Methods}

\subsection{Chemicals}

The following standards were used to determine sugars, organic acids, soluble polyphenol content, carotenoids and antioxidant capacity: sucrose, fructose and glucose; citric acid, malic acid, succinic acid and fumaric acid; gallic acid; $\alpha / \beta$-carotene, lutein, $\beta$-cryptoxanthin, violoxanthin, zeaxanthin; trolox solution from Sigma-Aldrich Chemie (Steinheim, Germany).

\subsection{Vegetal Material and Experimental Design}

Persimmon fruits from seven astringent cultivars (cv. Rojo Brillante; cv. Tone Wase; cv. Giboshi; cv. Kaki Tipo; cv. Aizumishirazu-A; cv. Giombo; cv. Hachiya) and three non-astringent cultivars (cv. O’gosho; cv. Hana Fuyu; cv. Jiro) were harvested from October to November in the persimmon germplasm collection hosted by the Instituto Valenciano de Investigaciones Agrarias (IVIA, Valencia, Spain). Harvesting was carried out when fruits reached a homogeneous full orange or reddish-orange colour depending on the cultivar. In all the cultivars, fruits presented a crisp texture with firmness values over $30 \mathrm{~N}$.

One homogeneous lot of 20 persimmon fruits from each cultivar was evaluated immediately after harvest. A 
second lot of 20 fruits from astringent cultivars was subjected to deastringency treatment under standard conditions ( $95 \% \mathrm{CO}_{2}$ at $20^{\circ} \mathrm{C}$ and $90 \% \mathrm{RH}$ for $24 \mathrm{~h}$ ). After deastringency treatment, fruits were kept at room temperature in an air atmosphere for $24 \mathrm{~h}$ to evaluate the changes associated with treatment application.

At harvest and after deastringency treatment (with astringent cultivars), besides measuring external colour and firmness, the following parameters were evaluated: soluble polyphenol content, total antioxidant capacity, total soluble solids, total and individual sugars, organic acids and carotenoids compounds. The astringency level was sensory-evaluated by a semi-trained panel. With astringent cultivars, acetaldehyde concentration was analysed at harvest and after deastringency treatment.

\subsection{Evaluation of External Skin Colour, Flesh Firmness, Acetaldehyde Production and Sensory Analysis}

External skin colour and flesh firmness were determined on 20 fruits. External colour was evaluated with a Minolta colorimeter (Model CR-300 Ramsey, NY, USA); Hunter parameters (“L”, “a”, "b”) were measured and the results were expressed as a colour index: $\mathrm{CI}=1000 \mathrm{a} / \mathrm{Lb}$ [11]. Fruit firmness was determined by a Texturometer Instron Universal Machine model 4301 (Instron Corp., Canton, MA, USA) using an 8-mm plunger and breaking the flesh in each fruit on $180^{\circ}$ sides after removing peel.

Acetaldehyde concentration was analysed by headspace gas chromatography, as described by Salvador et al. [11] and the results were expressed as $\mathrm{mg} 100 \mathrm{~mL}^{-1}$.

The sensory evaluation of astringency was performed on composite samples of three (peeled and sliced) fruits. A semi-trained panel of 8 - 10 people, who were familiar with persimmon fruits, was asked to evaluate astringency. A 4-point scale was used, where 0 was "no astringency" and 3 was "very high astringency". Samples were presented to panel members on trays labelled with random 3-digit codes and served at room temperature $\left(25^{\circ} \mathrm{C} \pm 1^{\circ} \mathrm{C}\right)$. Judges had to taste several segments of each sample to compensate, as far as possible, the biological variation of the material. Milk was provided for palate rinsing between samples.

\subsection{Determination of Soluble Polyphenol Content and Total Antioxidant Capacity}

The soluble polyphenol content of each cultivar was measured as gallic acid equivalents (GAE) using the Folin-Ciocalteau's phenol reagent (FC reagent) according to Taira [12]. The results were expressed as milligrams of GAE per $100 \mathrm{~g}$ of dried weight $(\mathrm{dw})$.

Total antioxidant capacity was determined as the antiradical activity of methanolic extracts, where $20 \mathrm{mg}$ of sample were homogenised with $2 \mathrm{~mL}$ of methanol $(80 \% \mathrm{v} / \mathrm{v})$. It was spectrophotometrically tested by measuring absorbance at $515 \mathrm{~nm}$ of free radical DPPH, adapted from Novillo et al. [13]. The obtained values were compared to the concentration-response curve of the standard Trolox solution expressed as micromoles of Trolox equivalents (TE) per $100 \mathrm{mg}$ of $\mathrm{dw}$.

\subsection{Extraction and HPLC Analysis of Sugars and Organic Acids}

The extraction and determination of sugars and organic acids were conducted from $50 \mathrm{mg}$ of sample and extracted with $1 \mathrm{~mL}$ of bi-distilled water. The extracted sample was centrifuged twice at 14,000 rpm for 15 min at $4^{\circ} \mathrm{C}$. The supernatant was filtered through $0.45 \mu \mathrm{m}$ filters and purified in a Sep-Pak C18 column. An analysis of sugars was performed in a Thermo Separation Products HPLC. Separation of sugars was done isocratically with Millipore water as a mobile phase, at a flow of $0.5 \mathrm{~mL} \cdot \mathrm{min}^{-1}$ in a fast carbohydrate column (Aminex HPX87-C column), $100 \times 7.8 \mathrm{~mm}$ i.d. (Bio Rad Laboratories, Hercules, CA, USA), which was preceded by a micro-guard cartridge, Carbo-C $30 \times 4.6 \mathrm{~mm}$ i.d. (Bio Rad Laboratories, Hercules, CA, USA) maintained at $75^{\circ} \mathrm{C}$ and attached to a refractive index detector (RID). Separation of the organic acids analysis was carried out in an Alliance liquid chromatographic system (Waters, Barcelona, Spain) equipped with a 2695 separation module, coupled to a 2996 photodiode array detector and a ZQ2000 mass detector. A thermostat column oven, an ICSep ICE-COREGEL 87H3 column (Transgenomic), an ICSep ICE-COREGEL 87H guard kit and an automatic injector were used for chromatographic separation. The Empower 2 software was used for data acquisition. Sample temperature was $5^{\circ} \mathrm{C}$ and column temperature was $35^{\circ} \mathrm{C}$. Capillary voltage was $3.0 \mathrm{kV}$, cone voltage was 23 $\mathrm{V}$, source temperature was $100^{\circ} \mathrm{C}$, desolvation temperature was $200^{\circ} \mathrm{C}$ and desolvation gas flow was $400 \mathrm{~L} / \mathrm{Hr}$. Full data acquisition was performed by scanning 100 to 400 uma in the centroid mode. The solvent system was 
an isocratic mobile phase of $0.1 \% \mathrm{H}_{2} \mathrm{SO}_{4}$ solution. The total run time was $20 \mathrm{~min}$ at $0.6 \mathrm{~mL} \cdot \mathrm{min}^{-1}$. The injection volume was $5 \mu \mathrm{L}$. The results were expressed as $\mu \mathrm{g} \cdot \mathrm{mg}^{-1} \cdot \mathrm{dw}$. Sucrose, glucose and fructose sugars were identified by comparing their retention time with a standard and they were quantified using an external calibration curve. Organic acid compounds were identified on the basis of comparing their retention times, UV-Vis spectra and mass spectrum data with the corresponding authentic standards. Concentrations were determined using an external calibration curve with citric acid ( $\mathrm{rT}=7.7 \mathrm{~min} ;[\mathrm{M}-\mathrm{H}]+191 \mathrm{~m} / \mathrm{z})$, malic acid (rT = $9.1 \mathrm{~min}$; $[\mathrm{M}-\mathrm{H}]+$ $133 \mathrm{~m} / \mathrm{z}$ ) and succinic acid (rT = $11.2 \mathrm{~min} ;[\mathrm{M}-\mathrm{H}]+117 \mathrm{~m} / \mathrm{z}$ ).

\subsection{Determination of Total Carotenoid Content and HPLC Analysis of Individual Carotenoids}

The total carotenoid content determination was conducted according to Koca et al. [14], where $50 \mathrm{mg}$ of dried sample were homogenised with $2 \mathrm{~mL}$ of hexane:acetone mixture (7:3). Carotenoid content was determined spectrophotometrically at $450 \mathrm{~nm}$ from the standard curve and expressed as micrograms of $\beta$-carotene equivalents ( $\beta$-CE) per $100 \mathrm{mg}$ of $\mathrm{dw}$.

Individual carotenoids were determined from $50 \mathrm{mg}$ of ground tissue and extracted in $1 \mathrm{~mL}$ cold ethanol and $0.8 \mathrm{~mL}$ hexane. The extraction mixture was centrifuged at $10,000 \mathrm{rpm}$ for $5 \mathrm{~min}$ at $4^{\circ} \mathrm{C}$. The upper organic phase was transferred to a new microcentrifuge tube. In order to avoid losses, saturated sodium chloride $(0.5 \mathrm{~mL})$ and hexane $(0.8 \mathrm{~mL})$ were added twice to the pellet and the mixture was recentrifuged. The organic phase was free of visible particulates and was, therefore, not filtered. The organic phase was evaporated under a nitrogen stream. For the saponification of persimmon carotenoids, residues were dissolved in $1 \mathrm{~mL}$ of methanolic potassium hydroxide (2 M) and $0.1 \%$ butylated hydroxytoluene was used to avoid oxidation. The mixture was left $3 \mathrm{~h}$ in the dark. It was transferred to a separatory funnel. Then $4 \mathrm{~mL}$ of $10 \%$ sodium chloride, plus $2 \mathrm{~mL}$ of hexane, were poured over to remove potassium hydroxide. The hexane layer was also washed with bi-distilled water until the rinse had a neutral $\mathrm{pH}$. Once again $2 \mathrm{~mL}$ of hexane were added to the potassium hydroxide to collect any remaining carotenoids. The combined hexane extracts were evaporated under a nitrogen stream. Samples were dissolved in $300 \mu \mathrm{L}$ of ethyl acetate and $10 \mu \mathrm{L}$ of were injected in reverse phase HPLC (Agilent 1200 series HPLC system (Santa Clara, CA)), including a model G1311A quaternary pump, a model G1367B autosampler, a model G1316A column oven and a model G13150 photodiode array detector. The column was an Agilent ZORBAX Eclipse XDB-C18, $5 \mu \mathrm{m}$ bead size, $4.6 \mathrm{~mm} \times 150 \mathrm{~mm}$, connected with an Eclipse XDB-C18 guard column. Column temperature was controlled at $30^{\circ} \mathrm{C}$ during HPLC runs. Data were processed by the Agilent ChemStation software. Separation of carotenoids pigments was achieved by modifying a previously established gradient elution programme [15]. The flow rate was $1 \mathrm{~mL} \cdot \mathrm{min}^{-1}$. The mobile phases were acetonitrile: $\mathrm{H}_{2} \mathrm{O}:$ triethylamine (900:99:1, v/v/v) (A) and ethyl acetate (B). The gradient elution programme was: 0 - 5 min, 100\% 75\% A; 5 - 10 min, 75\% - 30\% A; 10 - 13 min, 30\% - 0\% A; 13 - 14 min, 0\% - 100\%; 14 - 15 min, 100\% A. Data were collected at $440 \mathrm{~nm}, 477 \mathrm{~nm}$ and $296 \mathrm{~nm}$. Several carotenoids were identified based on retention time and spectrum compared to commercially available authentic standards. Their quantity was extrapolated from standard curves of authentic compounds and was corrected for extraction efficiency based on the $\beta$-apo-8'-carotenal internal recovery standard. Concentrations were expressed as $\mu \mathrm{g} \cdot \mathrm{kg}^{-1} \cdot \mathrm{dw}$.

The vitamin A value in fruits was calculated as retinol activity equivalents (RAE) using the following conversion according to [16]: $\mathrm{RAE}=[(\beta$-cryptoxanthin/12 $)+(\alpha$-carotene/12 $)+(\beta$-carotene/6) $]$.

\subsection{Statistical Analysis}

Data were subjected to an analysis of variance, and the multiple comparisons between means were determined by the least significant difference $(\mathrm{LSD})$ test $(\mathrm{P} \leq 0.05)$ using the Statgraphics Plus 5.1 software application (Manugistics Inc., Rockville, MD, USA).

\section{Results and Discussion}

\subsection{External Skin Colour, Flesh Firmness, Acetaldehyde Production and Sensory Evaluation}

External colour is the most widely used parameter as a non-destructive index for harvesting persimmon. In the present research, the fruits from all the cultivars were harvested in the commercial maturity stage, with an ex- 
ternal colour index that ranged from 15 to 20, and corresponded to homogeneous skin coloration from full orange to reddish-orange, depending on the cultivar (data not shown). Firmness at harvest was above $30 \mathrm{~N}$ for all the studied cultivars, values which allow persimmons with a crisp texture to be marketed. The application of deastringency treatment with $\mathrm{CO}_{2}$ to cultivars that were astringent at harvest neither modified fruit firmness nor skin colour. However, the treatment brought about a sharp rise in acetaldehyde content from values below 0.5 mg $100 \mathrm{~mL}^{-1}$ at harvest to values between 1 and $3 \mathrm{mg} 100 \mathrm{~mL}^{-1}$ (data not shown). This increase was due to exposing fruits to a high- $\mathrm{CO}_{2}$ atmosphere since acetaldehyde accumulates under partially or totally anaerobic conditions [17].

The sensory evaluation corroborated absence of astringency at harvest in the fruits of non-astringent cultivars (data not shown). It also revealed that deastringency treatment was effective for removing astringency in all the astringent cultivars, except "Hachiya”, in which panellists detected slight astringency after applying treatment.

\subsection{Study of Soluble Polyphenol Content and Antioxidant Capacity}

In persimmon, the soluble polyphenols that belong to the proanthocyanidin class are responsible for typical astringency since they interact with salivary proteins and give rise to the astringency sensation [18]. It is known that persimmons from both astringent and non-astringent cultivars are very astringent, with high soluble polyphenol content when fruit are small and immature. Nevertheless, while the fruits from astringent cultivars remain strongly astringent even when fruits are fully coloured, those from non-astringent cultivars lose astringency while growing on trees. It has been claimed that tannin cell development is continuous to late fruit growth stages in astringent cultivars, while tannin cells development stops in early fruit growth stages in non-astringent ones. Thus natural loss of astringency on trees is thought to be due to the dilution of tannins concentration on flesh as fruits grow [1].

In the present study, the fruits of the cultivars that were astringent at harvest showed high soluble polyphenol

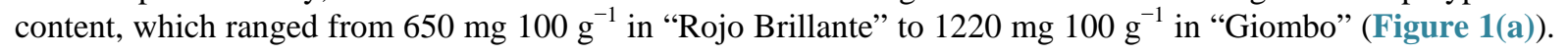

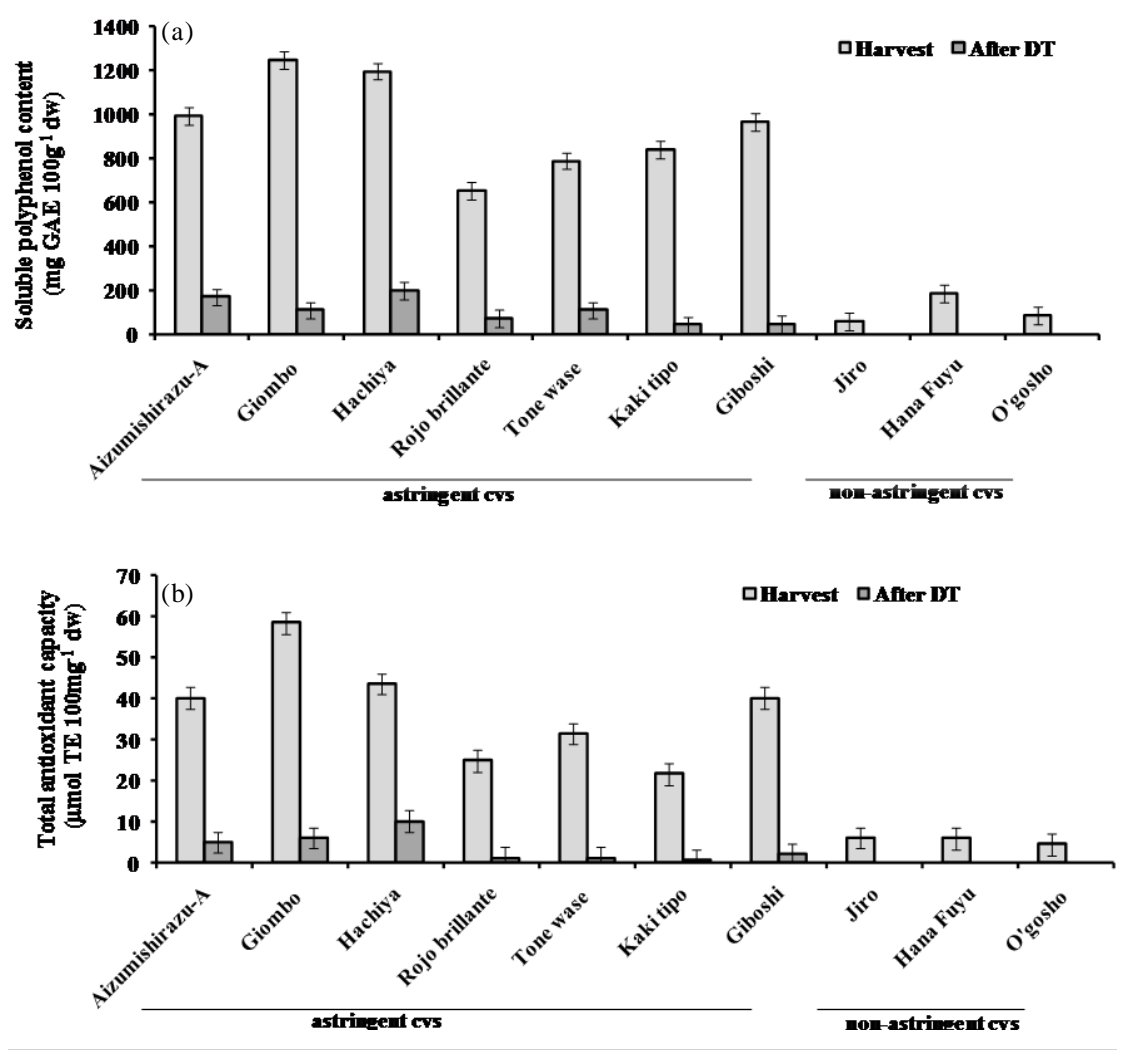

Figure 1. Soluble polyphenol content (a) and total antioxidant capacity (b) of ten persimmon cultivars at harvest and after deastringency treatment (DT). Vertical bars denote the LSD interval $(\mathrm{P}<0.05)$. 
Major differences in the soluble polyphenol contents among cultivars have been previously reported by Veberic et al. [8]. In contrast, the soluble polyphenol content of non-astringent cultivars was much lower, and they all showed values below $185 \mathrm{mg} 100 \mathrm{~g}^{-1}$.

As expected, when persimmons from astringent cultivars were subjected to deastringency treatment with a high $\mathrm{CO}_{2}$ concentration, soluble polyphenols drastically dropped, and similar values to those of non-astringent cultivars were given. The decline in soluble polyphenols in astringent cultivars ran in parallel to the sharp rise in acetaldehyde content observed after deastringency treatment. It is known that the insolubilisation of tannins, and consequently astringency removal, are mediated by the acetaldehyde generated under anaerobic conditions [13] [19].

After deastringency treatment, the concentration of soluble polyphenols vastly varied among cultivars; the highest values, $200 \mathrm{mg} 100 \mathrm{~g}^{-1}$, were observed in cultivar "Hachiya” which agrees with the sensory astringency detected by the panellists. Currently, there is no established threshold of soluble tannins that ensures lack of astringency in persimmon fruits. In fact, perception of astringency has been shown to be influenced by presence of other compounds, like acids and sugars [20] [21] and it is probably affected by the specific tannin composition of each cultivar [22]. However, it must be noted that after applying deastringency treatment to astringent cultivars, the concentration of soluble tannins lowered to similar values to those of naturally non-astringent cultivars.

The higher antioxidant capacity exhibited by astringency cultivars at harvest compared to non-astringent ones (Figure 1(b)) was related directly to content of polyphenols, which possess strong radical scavenging activity. It has been reported that polyphenols are the major antioxidant compounds in persimmon pulp [23]. Non-astringent cultivars gave values below $6 \mu \mathrm{mol}$ TE $100 \mathrm{mg}^{-1}$. However, the content among astringent cultivars varied vastly and presented values that ranged from 25 to $60 \mu \mathrm{mol} \mathrm{TE} 100 \mathrm{mg}^{-1}$ (Figure 1(b)). Similar results were obtained by Katsube et al. [24], who measured antioxidant activity by the DPPH radical method, and obtained more than one order magnitude higher in astringent persimmons than in non-astringent ones.

As observed with soluble polyphenol content, total antioxidant capacity also significantly lowered after subjecting astringent cultivars to deastringency treatment. Thus after $\mathrm{CO}_{2}$ treatment, most cultivars showed similar total antioxidant capacity values to those observed by non-astringent cultivars. The highest values, $10 \mu \mathrm{mol}$ TE $100 \mathrm{mg}^{-1}$, were detected in cultivar "Hachiya" while the lowest values, below $2 \mu \mathrm{mol} \mathrm{TE} 100 \mathrm{mg}^{-1}$, were given by "Rojo Brillante", "Tone Wase" and "Kaki Tipo" (Figure 1(b)). These results agree with those of Del Bubba et al. [9], who reported that the deastringency treatment with $\mathrm{CO}_{2}$ applied to cultivars "Kaki Tipo" and "Rojo Brillante" led to a 10 -fold drop in antioxidant capacity.

\subsection{Study of Sugars}

Table 1 shows the individual and total sugars in the 10 studied persimmon cultivars. The main sugars found in the flesh of all persimmon cultivars were sucrose, glucose and fructose, which agrees with previously reported studies [8] [9] [25].

After taking into account the individual and total sugars of astringent cultivars at harvest, "Tone wase" and "kaki Tipo" presented the highest content of glucose $\left(509.9-394.4 \mu \mathrm{g} \cdot \mathrm{mg}^{-1}\right)$ and fructose $(412.1$ - 335.7 $\mu \mathrm{g} \cdot \mathrm{mg}^{-1}$ ) and total sugars (1086 - $\left.996.7 \mu \mathrm{g} \cdot \mathrm{mg}^{-1}\right)$. The highest sucrose content value went to "Giombo" (401.8 $\left.\mu \mathrm{g} \cdot \mathrm{mg}^{-1}\right)$, "Rojo Brillante" (396.9 $\left.\mu \mathrm{g} \cdot \mathrm{mg}^{-1}\right)$ and "Kaki Tipo" (356.5 $\left.\mu \mathrm{g} \cdot \mathrm{mg}^{-1}\right)$, while "Tone Wase” obtained the lowest value $\left(74.7 \mu \mathrm{g} \cdot \mathrm{mg}^{-1}\right)$. Cultivars "Aizumishirazu-A", "Hachiya” and "Giboshi” showed the lowest sugar content values, similarly to that observed in non-astringent cultivars. The total sugar content in non-astringent cultivars was lower, and ranged from 433.6 to $609.4 \mu \mathrm{g} \cdot \mathrm{mg}^{-1}$. Cultivar "Hana Fuyu" presented a higher content of reducing sugars (glucose and fructose) than sucrose, while sucrose was found at the highest concentration, followed by glucose and fructose in "Jiro" and "O'gosho".

The effect of deastringency treatment on total sugar content strongly depends on the cultivar. While the total sugar content of "Aizumishirazu-A", "Hachiya" and "Giboshi" was not affected by deastringency treatment, in "Tone Wase”, "Rojo Brillante”, "Kaki Tipo” and "Giombo", the cultivars that presented the highest sugars level at harvest, deastringency treatment caused an important drop in the total sugar content to about half the original value. So when the fruits of all the astringent cultivars were ready to be marketed (after treatment deastringency) exhibited similar total sugars content to that of non-astringent cultivars.

Reduced total sugars after deastringency treatment was generally due to the sharp drop in sucrose in most cultivars, which even became undetectable in cultivars such as "Hachiya”, "Tone Wase”, "Kaki Tipo" and "Giboshi". It is noteworthy that cultivar "Aizumishirazu-A" was the only cultivar that showed no differences in sucrose 
Table 1. Sugars content $\left(\mu \mathrm{g} \cdot \mathrm{mg}^{-1} \cdot \mathrm{dw}\right)^{\mathrm{a}}$ of ten persimmon cultivars at harvest and after deastringency treatment (DT).

\begin{tabular}{|c|c|c|c|c|c|c|c|c|}
\hline & \multicolumn{2}{|c|}{ Sucrose } & \multicolumn{2}{|c|}{ Glucose } & \multicolumn{2}{|c|}{ Fructose } & \multicolumn{2}{|c|}{ Total sugars } \\
\hline & Harvest & After DT & Harvest & After DT & Harvest & After DT & Harvest & After DT \\
\hline \multicolumn{9}{|l|}{ astringent cvs } \\
\hline Aizumishirazu-A & 241.1 de & 248.9 de & 194.5 bc & 200.4 bc & 171.9 bc & 177.1 bc & $607.5 \mathrm{abc}$ & $626.5 \mathrm{bc}$ \\
\hline Giombo & $401.8 \mathrm{f}$ & 190.2 bc & 240.1 bcd & 196.6 bc & 201.7 bcd & 178.1 bc & 843.8 de & $564.9 \mathrm{ab}$ \\
\hline Hachiya & $147.6 \mathrm{ab}$ & nd & 281.5 def & $337.5 \mathrm{gh}$ & 232.6 cde & 288.7 fgh & 661.7 bc & $626.2 \mathrm{bc}$ \\
\hline Rojo brillante & $396.9 \mathrm{f}$ & $222.0 \mathrm{bcd}$ & $317.7 \mathrm{fg}$ & $158.8 \mathrm{ab}$ & 263.9 efg & 265.9 efg & 978.6 ef & $646.8 \mathrm{bc}$ \\
\hline Tone wase & 74.7 a & nd & $509.9 \mathrm{i}$ & 323.5 fg & $412.1 \mathrm{i}$ & $301.5 \mathrm{fgh}$ & 996.7 ef & $625.1 \mathrm{bc}$ \\
\hline Kaki tipo & $356.5 \mathrm{f}$ & nd & $394.4 \mathrm{~h}$ & 348.5 gh & $335.7 \mathrm{~h}$ & $318.8 \mathrm{gh}$ & $1086.6 \mathrm{f}$ & $667.3 \mathrm{bc}$ \\
\hline Giboshi & $143.3 \mathrm{ab}$ & nd & 204.3 bc & 265.4 cde & 183.7 bc & 250.8 def & $531.3 \mathrm{ab}$ & $516.2 \mathrm{ab}$ \\
\hline \multicolumn{9}{|l|}{ non-astringent cvs } \\
\hline Jiro & 310.8 ef & - & $152.16 \mathrm{ab}$ & - & $146.5 \mathrm{ab}$ & - & $516.2 \mathrm{ab}$ & - \\
\hline Hana Fuyu & 199.0 bc & - & 295.9 def & - & $277.2 \mathrm{fgh}$ & - & 609.4 bc & - \\
\hline O'gosho & $224.8 \mathrm{bcd}$ & - & 110.8 a & - & $97.9 \mathrm{a}$ & - & 433.6 a & - \\
\hline
\end{tabular}

${ }^{\mathrm{a}}$ Values are the mean of three independent determinations. For each sugar, values with different letters indicate significant differences $(\mathrm{P}<0.05)$. $n d$ : not detected.

content between values at harvest and those recorded after applying $\mathrm{CO}_{2}$ treatment. Glucose and fructose were much less affected by deastringency treatment. Glucose and fructose contents remained almost constant in most cultivars, except cultivars "Rojo Brillante" and "Tone Wase”. Glucose in "Rojo Brillante” significantly decreased after applying treatment (from values of $317.7 \mu \mathrm{g} \cdot \mathrm{mg}^{-1}$ at harvest to values of $158.8 \mu \mathrm{g} \cdot \mathrm{mg}^{-1}$ after treatment), while "Tone Wase" showed a more reduced decline for glucose (from values of $509.9 \mu \mathrm{g} \cdot \mathrm{mg}^{-1}$ to $323.5 \mu \mathrm{g} \cdot \mathrm{mg}^{-1}$ ) and fructose (from $412.1 \mu \mathrm{g} \cdot \mathrm{mg}^{-1}$ to $301.5 \mu \mathrm{g} \cdot \mathrm{mg}^{-1}$ ). The results obtained in the present work agree with Ittah [25], who reported that deastringency treatment in $\mathrm{CO}_{2}$ atmospheres reduces the total sugars content and diminishes sucrose starts when $\mathrm{CO}_{2}$ treatment commences, while changes in glucose and fructose content are very gradual. This reduction in total sugars due with deastringency treatment can be explained by a possible glycoside formation between soluble tannins and soluble sugars.

The reduced sucrose content in most cultivars after deastringency treatment could be due to induced invertase activity through the tannin insolubilisation process during deastringency. In previous studies, the decline of sucrose that occurred in some astringent persimmon fruits during fruit growth and ripening have been attributed to an increase of invertase activity coupled with a decrease of soluble tannins [9] as an in vitro study has demonstrated the strong inhibition of this enzyme by gallic and tannin acids [26]. It has also been reported that fruit enzymatic systems, such as sucrose synthetase, invertase, fructose isomerase, cellulose and enzymes from the gluconeogenesis pathway, are involved with fruits under anaerobic conditions [27] [28].

\subsection{Study of Organic Acids}

Citric acid, malic acid and succinic acid were the main organic acids found in the present study, while fumaric acid was found in trace amounts (Table 2). At harvest, the total organic acids content ranged from $15.8 \mu \mathrm{g} \cdot \mathrm{mg}^{-1}$ to $30.9 \mu \mathrm{g} \cdot \mathrm{mg}^{-1}$. Citric acid content was over $5.3 \mu \mathrm{g} \cdot \mathrm{mg}^{-1}$ among all the cultivars, except non-astringent cultivars "Hana Fuyu” and "O’gosho", which presented lower values. Malic acid content was over $10 \mu \mathrm{g} \cdot \mathrm{mg}^{-1}$ in astringent cultivars such as "Rojo brillante”, “Tone wase”, "Kaki tipo”, and also in non-astringent cultivars "Jiro” and "O'gosho". The lowest value of this acid was shown for "Giombo" $\left(4.3 \mu \mathrm{g} \cdot \mathrm{mg}^{-1}\right)$. It is noteworthy that succinic acid content was higher in astringent cultivars, and "Giombo" is highlighted because it showed the highest values $\left(19.3 \mu \mathrm{g} \cdot \mathrm{mg}^{-1}\right)$. Non-astringent cultivars gave values below $5 \mu \mathrm{g} \cdot \mathrm{mg}^{-1}$ (Table 2).

Although the effect of deastringency treatment on organic acids has not been previously addressed, a reduction 
Table 2. Organic acids content $\left(\mu \mathrm{g} \cdot \mathrm{mg}^{-1} \cdot \mathrm{dw}\right)^{\mathrm{a}}$ of ten persimmon cultivars at harvest and after deastringency treatment (DT).

\begin{tabular}{|c|c|c|c|c|c|c|c|c|}
\hline & \multicolumn{2}{|c|}{ Citric acid } & \multicolumn{2}{|c|}{ Malic acid } & \multicolumn{2}{|c|}{ Succinic acid } & \multicolumn{2}{|c|}{ Total organic acids } \\
\hline & Harvest & After DT & Harvest & After DT & Harvest & After DT & Harvest & After DT \\
\hline \multicolumn{9}{|l|}{ astringent cvs } \\
\hline Aizumishirazu-A & $6.2 \mathrm{bc}$ & $5.3 \mathrm{~b}$ & $6.2 \mathrm{abc}$ & $8.3 \mathrm{c}$ & $6.1 \mathrm{ab}$ & $5.9 \mathrm{ab}$ & $18.5 a b$ & 19.5 bc \\
\hline Giombo & $7.3 \mathrm{~d}$ & $6 \mathrm{bc}$ & $4.3 \mathrm{a}$ & $5.2 \mathrm{ab}$ & $19.3 \mathrm{~g}$ & $16.6 \mathrm{f}$ & $30.9 \mathrm{f}$ & $27.8 \mathrm{ef}$ \\
\hline Hachiya & 6.4 bcd & $5.6 \mathrm{~b}$ & $6.4 \mathrm{abc}$ & $7.6 \mathrm{bc}$ & $8.7 \mathrm{~cd}$ & $8.6 \mathrm{~cd}$ & 21.5 bc & 21.8 bc \\
\hline Rojo brillante & $5.3 \mathrm{~b}$ & $5.7 \mathrm{~b}$ & 11.1 de & $8.7 \mathrm{~cd}$ & $8 \mathrm{~cd}$ & $9.2 \mathrm{~d}$ & $24.4 \mathrm{~d}$ & $23.6 \mathrm{~d}$ \\
\hline Tone wase & 6.7 bcd & $7 \mathrm{~d}$ & $11.1 \mathrm{e}$ & $12.3 \mathrm{e}$ & $8 \mathrm{~cd}$ & $7.5 \mathrm{bcd}$ & 25.8 de & $26.8 \mathrm{de}$ \\
\hline Kaki tipo & $6.8 \mathrm{bcd}$ & $5.5 \mathrm{~b}$ & 10.7 de & 10.8 de & $6.2 \mathrm{ab}$ & $7.1 \mathrm{bc}$ & $23.7 \mathrm{~d}$ & $23.4 \mathrm{~d}$ \\
\hline Giboshi & $7.2 \mathrm{~d}$ & 6.4 bcd & $7.2 \mathrm{bc}$ & $8.4 \mathrm{c}$ & $11.7 \mathrm{e}$ & $12.2 \mathrm{e}$ & 26.1 de & 27 de \\
\hline \multicolumn{9}{|l|}{ non-astringent cvs } \\
\hline Jiro & 6 bc & - & $11.3 \mathrm{e}$ & - & $4.8 \mathrm{a}$ & - & $22.1 \mathrm{~cd}$ & - \\
\hline Hana Fuyu & $4.7 \mathrm{ab}$ & - & $6.6 \mathrm{abc}$ & - & $4.5 \mathrm{a}$ & - & 15.8 a & - \\
\hline O'gosho & 3.8 a & - & $11.5 \mathrm{e}$ & - & $4.5 \mathrm{a}$ & - & 19.8 bc & - \\
\hline
\end{tabular}

${ }^{\mathrm{a}}$ Values are the mean of three independent determinations. For each organic acid, values with different letters indicate significant differences $(\mathrm{P}<$ 0.05). nd: not detected.

in their content was expected since it is known that high $\mathrm{CO}_{2}$ atmospheres induce changes in organic acid metabolism in other fruits, such as strawberry or cherimoya [29] [30]. Nevertheless in the present study, deastringency treatment did not affect the total organics acid content, and slightly modified individual organic acids.

The organic acids content found in the present study was higher than those reported by Veberic et al. [8], which is not surprising given the maturity stage of the fruit evaluated in each case. Fruits were analysed herein in the "ready-to-eat" maturity stage, while the evaluations of Veberic et al. [8] were made with fully ripened fruit. It has been reported that during fruit ripening, metabolic processes led to a considerable loss in organic acid in persimmon fruits [31].

\subsection{Study of Total and Individual Carotenoids}

Figure 2 depicts the total carotenoid content at harvest and after submitting astringent cultivars to the $\mathrm{CO}_{2}$ treatment. At harvest the total content greatly varied among the ten cultivars; cultivar "Hachiya” had the highest content (above $100 \mu \mathrm{g} \beta$-CE $100 \mathrm{~g}^{-1}$ ), while the lowest values went to cultivar "Rojo Brillante” and “O'gosho”, with 20 and $23.5 \mu \mathrm{g} \beta$-CE $100 \mathrm{~g}^{-1}$, respectively. All the other cultivars showed values that ranged from 40 to 80 $\mu \mathrm{g} \beta$-CE $100 \mathrm{~g}^{-1}$.

The individual carotenoids detected by HPLC in persimmon flesh were lutein, violoxanthin, zeaxanthin, $\beta$-cryptoxanthin and $\beta$-carotene (Table 3). $\beta$-cryptoxanthin was the predominant carotenoid found at harvest in all the studied cultivars. This xanthophyll has also been reported in previous studies as the main carotenoid in persimmon flesh [8] [10] [32]-[34]. The relative levels among zeaxanthin, lutein and $\beta$-carotene were cultivar-dependent. Violoxanthin was the lowest carotenoid found in all the cultivars.

Deastringency treatment led to an increase in the total carotenoids content compared to the values recorded at harvest in some cultivars, such as “Aizumishirazu-A”, "Giombo” and "Giboshi” (Figure 2), which coincides with the changes observed in individual carotenoids (Table 3). Thus the content of all the individual carotenoids content in cultivars "Aizumishirazu-A" and "Giombo" significantly increased after $\mathrm{CO}_{2}$ treatment, while the content of $\beta$-cryptoxanthin and $\beta$-carotene in "Giboshi” mainly increased. Very few studies have addressed the effect of deastringency treatment on carotenoid content in persimmon. Plaza et al. [35] observed that the carotenoids content of persimmons subjected to high pressure remained unchanged when applied to fruits in a mid-season maturity stage. Yet when this treatment was assayed in fruits in an advanced maturity stage, it led to 


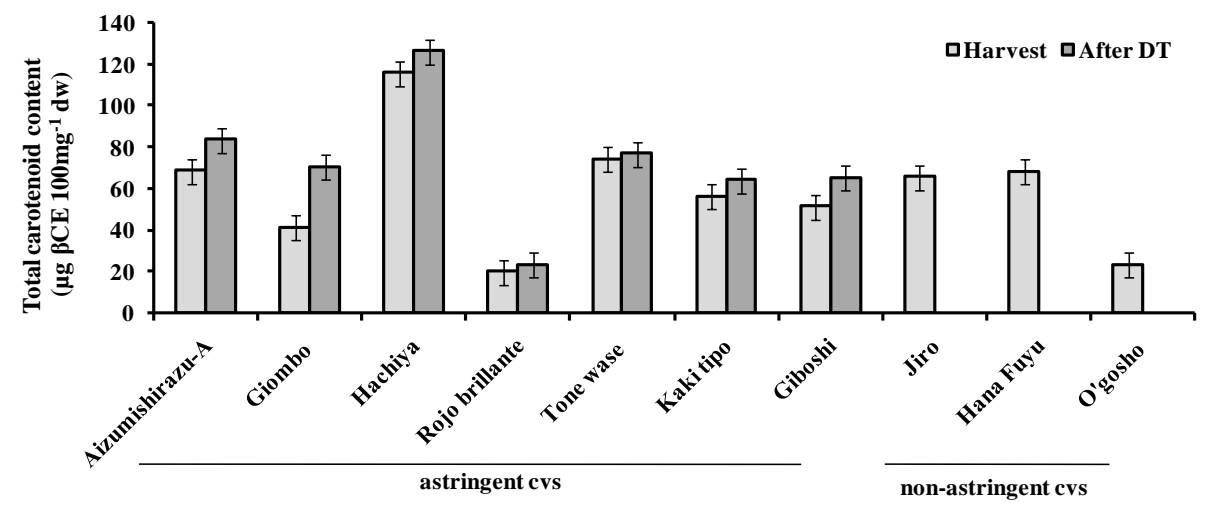

Figure 2. Total carotenoid content of ten persimmon cultivars at harvest and after deastringency treatment (DT). Vertical bars denote the LSD interval $(\mathrm{P}<0.05)$.

Table 3. Individual carotenoids $\left(\mu \mathrm{g} \cdot \mathrm{kg}^{-1} \cdot \mathrm{dw}\right)^{\mathrm{a}}$ of ten persimmon cultivars at harvest and after deastringency treatment (DT).

\begin{tabular}{|c|c|c|c|c|c|c|c|c|c|c|c|c|}
\hline & \multicolumn{2}{|c|}{ Lutein } & \multicolumn{2}{|c|}{ Violoxanthin } & \multicolumn{2}{|c|}{ Zeaxanthin } & \multicolumn{2}{|c|}{$\beta$-Cryptoxanthin } & \multicolumn{2}{|c|}{$\beta$-Carotene } & \multicolumn{2}{|c|}{ RAE } \\
\hline & Harvest & After DT & Harvest & After DT & Harvest & After DT & Harvest & After DT & Harvest & After DT & Harvest & After DT \\
\hline \multicolumn{13}{|l|}{ astringent cvs } \\
\hline Aizumishirazu-A & 183.9 bc & $422.6 \mathrm{gh}$ & $22.2 \mathrm{a}$ & $60.4 \mathrm{~cd}$ & 231.6 de & $298.1 \mathrm{fg}$ & $392.3 \mathrm{bcd}$ & $547.4 \mathrm{def}$ & 89.9 bcd & $158 \mathrm{~g}$ & $47.7 \mathrm{~cd}$ & 71.9 fg \\
\hline Giombo & $69.6 \mathrm{a}$ & $328.2 \mathrm{ef}$ & 45.6 abcd & 112.7 ef & 134.9 bc & 212.2 de & $267.9 \mathrm{~b}$ & 706.6 e & $68.9 \mathrm{ab}$ & 112.7 def & $33.8 \mathrm{~b}$ & $77.7 \mathrm{gh}$ \\
\hline Hachiya & $235.2 \mathrm{~cd}$ & $229.8 \mathrm{~cd}$ & $21.2 \mathrm{a}$ & $25.4 \mathrm{ab}$ & $445.4 \mathrm{~h}$ & $397.3 \mathrm{~h}$ & $771.1 \mathrm{e}$ & 801.8 e & $213.1 \mathrm{~h}$ & $212 \mathrm{~h}$ & $99.8 \mathrm{i}$ & $102.2 \mathrm{i}$ \\
\hline Rojo brillante & $97.8 \mathrm{ab}$ & $225.4 \mathrm{~cd}$ & 33.7 abc & $54.8 \mathrm{bcd}$ & $70.1 \mathrm{a}$ & $84.6 \mathrm{ab}$ & $325.4 \mathrm{~b}$ & $291.3 \mathrm{~b}$ & $70.4 \mathrm{ab}$ & 90.1 bcd & 38.9 c & 39.3 bc \\
\hline Tone wase & $445.7 \mathrm{~h}$ & $462.7 \mathrm{hi}$ & 49.1 abcd & $64.9 \mathrm{~d}$ & $261.5 \mathrm{ef}$ & $334.5 \mathrm{~g}$ & $510.4 \mathrm{~cd}$ & $459.1 \mathrm{~cd}$ & 80.7 abc & 95.6 bcde & 56 de & 54.2 def \\
\hline Kaki tipo & $545.5 .9 \mathrm{i}$ & $429.8 \mathrm{gh}$ & 95.9 e & $99.8 \mathrm{e}$ & 224.2 de & $180.6 \mathrm{~cd}$ & 508.7 cd & $538.9 \mathrm{~d}$ & 106.1 cde & 119 def & 60.1 def & 64.7 ef \\
\hline Giboshi & $350.2 \mathrm{fg}$ & 382.1 efgh & $132.8 \mathrm{fg}$ & $154.1 \mathrm{~g}$ & 259.7 ef & 263.7 ef & $488.9 \mathrm{~cd}$ & $686.1 \mathrm{e}$ & 102.7 cde & $143.6 \mathrm{fg}$ & 57.9 de & $81.1 \mathrm{gh}$ \\
\hline Jiro & 292.7 de & - & $60 \mathrm{~cd}$ & - & 177.9 cde & - & 800.8 e & - & 121.6 ef & - & $87 \mathrm{~h}$ & - \\
\hline Hana Fuyu & $296.5 \mathrm{ef}$ & - & $95.1 \mathrm{e}$ & - & 292.2 ghi & - & $502.9 \mathrm{~cd}$ & - & 121 def & - & $62.1 \mathrm{ef}$ & - \\
\hline O'gosho & 39.7 a & - & $27.1 \mathrm{ab}$ & - & $100.4 \mathrm{ab}$ & - & 90.8 a & - & $56.3 \mathrm{a}$ & - & $17 \mathrm{a}$ & - \\
\hline
\end{tabular}

${ }^{\mathrm{a}}$ Values are the mean of three independent determinations. For each organic acid, values with different letters indicate significant differences $(\mathrm{P}<0.05)$. nd: not detected.

increased carotenoids content, probably due to modifications in their bioaccessibility. The retinal activity equivalent (RAE) provided information about dietary intake of provitamin A carotenoids. In the present study, cultivars "Jiro" and "Hachiya" presented the highest RAE values (102.14 and $126.99 \mu \mathrm{g} \cdot \mathrm{kg}^{-1}$, respectively), mainly due to their high $\beta$-cryptoxanthin content.

\section{Conclusion}

Persimmons harvested with a firm texture that are to be commercialised as "ready-to-eat crisp" are rich in sugars (glucose, fructose and sucrose), organic acids (citric acid, malic acid and succinic) and carotenoids ( $\beta$-cryptoxanthin, lutein, violoxanthin, zeaxanthin, and $\beta$-carotene). The relative content of these compounds heavily depends on the cultivar, but astringent cultivars generally present a higher content of sugars and organic acids than non-astringent ones. At harvest, the fruits of astringent cultivars show especially high soluble polyphenols content and total antioxidant capacity. However when this fruit was submitted to deastringency treatment with $\mathrm{CO}_{2}$, the values of both soluble polyphenols content and total antioxidant capacity lowered, similarly to those of the naturally non-astringent fruits. Deastringency treatment also induced changes in fruit carotenoids and sugar composition. 


\section{Acknowledgements}

This study has been supported by the Spanish Ministry of Economy and Competitiveness (Project INIA-RTA 2013-00043-02-00) and EU the FEDER Programme.

\section{References}

[1] Yonemori, K. and Matsushima, J. (1987) Changes in Tannin Cell Morphology with Growth and Development of Japanese Persimmon Fruit. Journal of American Society for Horticultural Science, 112, 818-821.

[2] Santos-Buelga, C. and Scalbert, A. (2000) Proanthocyanidins and Tannin-Like Compounds-Nature, Occurrence, Dietary Intake and Effects on Nutrition and Health. Journal of the Science of Food and Agriculture, 80, 1094-1117. http://dx.doi.org/10.1002/(SICI)1097-0010(20000515)80:7<1094::AID-JSFA569>3.0.CO;2-1

[3] Giordani, E., Doumett, S., Nin, S. and Del Bubba, M. (2011) Selected Primary and Secondary Metabolites in Fresh Persimmon (Diospyros kaki Thunb.): A Review of Analytical Methods and Current Knowledge of Fruit Composition and Health Benefits. Food Research International, 44, 1752-1767. http://dx.doi.org/10.1016/j.foodres.2011.01.036

[4] Gorinstein, S., Kulasek, G.W., Bartnikowska, E., Leontowicz, M., Zemser, M., Morawiec, M. and Trakhtenberg, S. (2000) The Effects of Diets, Supplemented with Either Whole Persimmon or Phenol-Free Persimmon, on Rats Fed Cholesterol. Food Chemistry, 70, 303-308. http://dx.doi.org/10.1016/S0308-8146(00)00072-8

[5] Gorinstein, S., Leontowicz, H., Leontowicz, M., Jesion, I., Namiesnik, J., Drzewiecki, J., Park, Y.S., Ham, K.S., Giordani, E. and Trakhtenberg, S. (2011) Influence of Two Cultivars of Persimmon on Atherosclerosis Indices in Rats Fed Cholesterol-Containing Diets: Investigation in Vitro and in Vivo. Nutrition, 27, 838-846. http://dx.doi.org/10.1016/j.nut.2010.08.015

[6] Rao, A. and Rao, L.G. (2007) Carotenoids and Human Health. Pharmacological Research, 55, 207-216. http://dx.doi.org/10.1016/j.phrs.2007.01.012

[7] Park, Y.S., Jung, S.T., Kang, S.G., Delgado-Licon, E., Ayala, A.L.M., Tapia, M.S., Martín-Belloso, O., Trakhtenberg, S. and Gorinstein, S. (2006) Drying of Persimmons (Diospyros kaki L.) and the Following Changes in the Studied Bioactive Compounds and the Total Radical Scavenging Activities. Food Science and Technology, 39, 748-755. http://dx.doi.org/10.1016/j.lwt.2005.05.014

[8] Veberic, R., Jurhar, J., Mikulic-Petkovsek, M., Stampar, F. and Schmitzer, V. (2010) Comparative Study of Primary and Secondary Metabolites in 11 Cultivars of Persimmon Fruit (Diospyros kaki L.). Food Chemistry, 119, 477-483. http://dx.doi.org/10.1016/j.foodchem.2009.06.044

[9] Del Bubba, M., Giordani, E., Pippucci, L., Cincinelli, A., Checchini, L. and Galvan, P. (2009) Changes in Tannins, Ascorbic Acid and Sugar Content in Astringent Persimmons during On-Tree Growth and Ripening and in Response to Different Postharvest Treatments. Journal of Food Composition and Analysis, 22, 668-677. http://dx.doi.org/10.1016/j.jfca.2009.02.015

[10] Zhou, C., Zhao, D., Sheng, Y., Tao, J. and Yang, Y. (2011) Carotenoids in Fruits of Different Persimmon Cultivars. Molecules, 16, 624-636. http://dx.doi.org/10.3390/molecules16010624

[11] Salvador, A., Arnal, L., Monterde, A. and Cuquerella, J. (2004) Reduction of Chilling Injury Symptoms in Persimmon Fruit cv. "Rojo Brillante” by 1-MCP. Postharvest Biology and Technology, 33, 285-291. http://dx.doi.org/10.1016/j.postharvbio.2004.03.005

[12] Taira, S. (1995) Astringency in Persimmon. In: Linskens, H. and Jackson, J., Eds., Fruit Analysis, Springer Berlin, Heidelberg, 97-110.

[13] Novillo, P., Salvador, A., Magalhaes, T. and Besada, C. (2014) Deastringency Treatment with $\mathrm{CO}_{2}$ Induces Oxidative Stress in Persimmon Fruit. Postharvest Biology and Technology, 92, 16-22. http://dx.doi.org/10.1016/j.postharvbio.2013.12.019

[14] Koca, N., Burdurlu, H.S. and Karadeniz, F. (2007) Kinetics of Colour Changes in Dehydrated Carrots. Journal of Food Engineering, 78, 449-455. http://dx.doi.org/10.1016/j.jfoodeng.2005.10.014

[15] Tian, L. and DellaPenna, D. (2001) Characterization of a Second Carotenoid $\beta$-Hydroxylase Gene from Arabidopsis and Its Relationship to the LUT1 Locus. Plant Molecular Biology, 47, 379-388. http://dx.doi.org/10.1023/A:1011623907959

[16] Wright, K.P. and Kader, A.A. (1997) Effect of Controlled-Atmosphere Storage on the Quality and Carotenoid Content of Sliced Persimmons and Peaches. Postharvest Biology and Technology, 10, 89-97. http://dx.doi.org/10.1016/S0925-5214(96)00062-2

[17] Pesis, E. (2005) The Role of the Anaerobic Metabolites, Acetaldehyde and Ethanol, in Fruit Ripening, Enhancement of Fruit Quality and Fruit Deterioration. Postharvest Biology and Technology, 37, 1-19. http://dx.doi.org/10.1016/j.postharvbio.2005.03.001 
[18] Tarascou, I., Souquet, J., Mazauric, J., Carrillo, S., Coq, S., Canon, F., Fulcrand, H. and Cheynier, V. (2010) The Hidden Face of Food Phenolic Composition. Archives of Biochemistry and Biophysics, 501, 16-22. http://dx.doi.org/10.1016/j.abb.2010.03.018

[19] Matsuo, T. and Itoo, S. (1982) A Model Experiment for De-Astringency of Persimmon Fruit with High Carbon Dioxide Treatment: In Vitro Gelation of Kaki-Tannin by Reacting with Acetaldehyde. Agricultural and Biological Chemistry, 46, 683-689. http://dx.doi.org/10.1271/bbb1961.46.683

[20] Lyman, B.J. and Green, B. (1990) Oral Astringency: Effects of Repeated Exposure and Interactions with Sweeteners. Chemical Senses, 15, 151-164. http://dx.doi.org/10.1093/chemse/15.2.151

[21] Siebert, K.J. and Chassy, A.W. (2003) An Alternate Mechanism for the Astringency Sensation of Acids. Food Quality and Preferences, 15, 13-18. http://dx.doi.org/10.1016/S0950-3293(02)00221-5

[22] Suzuki, T., Someya, S., Hu, F. and Tanokura, M. (2005) Comparative Study of Catechin Compositions in Five Japanese Persimmons (Diospyros kaki). Food Chemistry, 93, 149-152. http://dx.doi.org/10.1016/j.foodchem.2004.10.017

[23] Gu, H.F., Li, C.M., Xu, Y.J., Hu, W.F., Chen, M.H. and Wan, Q.H. (2008) Structural Features and Antioxidant Activity of Tannin from Persimmon Pulp. Food Research International, 41, 208-217. http://dx.doi.org/10.1016/j.foodres.2007.11.011

[24] Katsube, T., Tabata, H., Ohta, Y., Yamasaki, Y., Anuurad, E., Shiwaku, K. and Yamane, Y. (2004) Screening for Antioxidant Activity in Edible Plant Products: Comparison of Low-Density Lipoprotein Oxidation Assay, DPPH Radical Scavenging Assay, and Folin-Ciocalteu Assay. Journal of Agricultural and Food Chemistry, 52, 2391-2396. http://dx.doi.org/10.1021/jf035372g

[25] Ittah, Y. (1993) Sugar Content Changes in Persimmon Fruits (Diospyros kaki L.) during Artificial Ripening with $\mathrm{CO}_{2}$ : A Possible Connection to Deastringency Mechanisms. Food Chemistry, 48, 25-29. http://dx.doi.org/10.1016/0308-8146(93)90216-3

[26] Chen, J.L., Ni, H.X., Sun, J.R. and Cheng, D.F. (2003) Effects of Major Secondary Chemicals of Wheat Plants on Enzyme Activity in Sitobion avenae. Acta Entomologica Sinica, 46, 144-149.

[27] Borsani, J., Budde, C.O., Porrini, L., Lauxmann, M.A., Lombardo, V.A., Murray, R., Andreo, C.S., Drincovich, M.F. and Lara, M.V. (2009) Carbon Metabolism of Peach Fruit after Harvest: Changes in Enzymes Involved in Organic Acid and Sugar Level Modifications. Journal of Experimental Botany, 60, 1823-1837. http://dx.doi.org/10.1093/jxb/erp055

[28] Lara, M.V., Budde, C.O., Porrini, L., Borsani, J., Murray, R., Andreo, C.S. and Drincovich, M.F. (2011) Peach (Prunus persica) Fruit Response to Anoxia: Reversible Ripening Delay and Biochemical Changes. Plant and Cell Physiology, 52, 392-403. http://dx.doi.org/10.1093/pcp/pcq200

[29] Alique, R. and Oliveira, G.S. (1994) Changes in Sugars and Organic Acids in Cherimoya (Annona cherimola Mill.) Fruit under Controlled Atmosphere Storage. Journal of Agricultural and Food Chemistry, 42, 799-803. http://dx.doi.org/10.1021/jf00039a040

[30] Holcroft, D.M. and Kader, A.A. (1999) Controlled Atmosphere-Induced Changes in pH and Organic Acid Metabolism May Affect Color of Stored Strawberry Fruit. Postharvest Biology and Technology, 17, 19-32. http://dx.doi.org/10.1016/S0925-5214(99)00023-X

[31] Daood, H.G., Biacs, P., Czinkotai, B. and Hoschke, Á. (1992) Chromatographic Investigation of Carotenoids, Sugars and Organic Acids from Diospyros kaki Fruits. Food Chemistry, 45, 151-155. http://dx.doi.org/10.1016/0308-8146(92)90027-Y

[32] De Ancos, B., González, E.M. and Cano, M.P. (2000) Ellagic Acid, Vitamin C, and Total Phenolic Contents and Radical Scavenging Capacity Affected by Freezing and Frozen Storage in Raspberry Fruit. Journal of Agricultural and Food Chemistry, 48, 4565-4570. http://dx.doi.org/10.1021/jf0001684

[33] Homnava, A., Payne, J., Koehler, P. and Eitenmiller, R. (1990) Provitamin a (Alpha-Carotene, Beta-Carotene and Beta-Cryptoxanthin) and Ascorbic Acid Content of Japanese and American Persimmons. Journal of Food Quality, 13, 8595. http://dx.doi.org/10.1111/j.1745-4557.1990.tb00009.x

[34] Kondo, S., Yoshikawa, H. and Katayama, R. (2004) Antioxidant Activity in Astringent and Non-Astringent Persimmons. Journal of Horticultural Science \& Biotechnology, 79, 390-394.

[35] Plaza, L., Colina, C., de Ancos, B., Sánchez-Moreno, C. and Cano, M.P. (2012) Influence of Ripening and Astringency on Carotenoid Content of High-Pressure Treated Persimmon Fruit (Diospyros kaki L.). Food Chemistry, 130, 591-597. http://dx.doi.org/10.1016/j.foodchem.2011.07.080 